\title{
Ocorrência de Phaops thunbergi (Coleoptera: Curculionidae) em Acacia mearnsii De Wild.
}

\author{
Occurrence of Phaops thunbergi (Coleoptera: Curculionidae) in Acacia mearnsii De Wild.
}

\author{
Leonardo da Silva Oliveira ${ }^{1 *}$ Ervandil Corrêa Costa $^{2}$ Edison Bisognin Cantarelli ${ }^{1}$ \\ Edison Rogério Perrando ${ }^{1}$ Dijalmas Dal Pozza Pacheco ${ }^{3}$
}

\begin{abstract}
Observou-se, pela primeira vez, Phaops thunbergi RESUMO (Dalman, 1823) (Coleoptera: Curculionidae) danificando plantas de acácia-negra (Acacia mearnsii De Wild.) no Brasil. A incidência ocorreu no município de Butiá, Rio Grande do Sul (30¹3'56.1” Sul, 5158'34.6” Oeste), em janeiro de 2004.
\end{abstract}

Palavras-chave: Acácia-negra; inseto; desfolhador.

\section{ABSTRACT}

The occurrence of Phaops thunbergi (Dalman, 1823) (Coleoptera: Curculionidae) attacking plants of black wattle (Acacia mearnsii De Wild.) in Brazil was observed. It was recorded for the first time in Butiá, State of Rio Grande do Sul

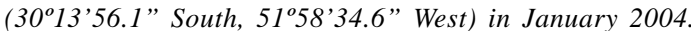

Key words: Black wattle; insect; defoliator.

Na década de trinta, no município de Estrela, Rio Grande do Sul, formam estabelecidos os primeiros plantios comerciais de Acacia mearnsii De Wild. (acácia-negra) no Brasil (OLIVEIRA, 1960). Essa espécie, originária da Austrália, foi introduzida com a finalidade de se obter tanino de sua casca e madeira para fins energético, e posteriormente, para produção de papel e celulose. Atualmente, a acácia-negra é cultivada em mais de 10 mil pequenas propriedades rurais, exercendo um relevante papel socioeconômico. O objetivo deste estudo é relatar a ocorrência do Curculionidae Phaops thunbergi, associado a povoamentos homogêneos de acácia-negra como inseto filófago.

A superfamília Curculionoidea é a mais numerosa da ordem Coleoptera, com cerca de 45.000 espécies descritas. Praticamente todas as suas espécies alimentam-se de matéria vegetal e grande parte destas são importantes pragas agrícolas e florestais (BORROR \& DELONG, 1969). No Brasil, espécies da família Curculionidae, incluindo Gonipterus gibberus, em Eucalyptus sp. (ANDRADE, 1928), e espécies de Naupactus, em Pinus taeda (PEDROSA-MACEDO, 1993), são consideradas insetos-praga para essências florestais. Até o momento, não há registro de espécies de Curculionidae causando danos em plantios de acácia-negra no Brasil.

Em janeiro de 2004, foi constatada a desfolha de acácia-negra por um Curculionidae, em área experimental da Empresa SETA S.A. (30¹3’56.1”' Sul, 5158’34.6” Oeste), no município de Butiá, região da

\footnotetext{
${ }^{1}$ Programa de Pós-graduação em Engenharia Florestal, Centro de Ciências Rurais, Universidade Federal de Santa Maria, (CCR/ UFSM), Campus Universitário, Prédio 44, 97105-900, Santa Maria, RS, Brasil. E-mail: leonardo76rs@yahoo.com.br. *Autor para correspondência.

${ }^{2}$ Departamento de Defesa Fitossanitária (CCR/UFSM), Campus Universitário, Prédio 42, 97105-900, Santa Maria, RS, Brasil. Email: eccosta@smail.ufsm.br.

${ }_{3}^{3}$ SETA S.A., Rua Rudolfo Schmeling, 163, 95860-000, Taquari, RS, Brasil. E-mail: dijalmas@seta-as.com.br
} 
serra do sudeste do Estado do Rio Grande do Sul. Espécimens foram coletados e enviados ao Centro de Estudos Faunísticos e Ambientais (CDZoo) da Universidade Federal do Paraná (UFPR). Os insetos foram identificados pelo Prof. Dr. Germano RosadoNeto como Phaops thunbergi (Dalman, 1823) (Coleoptera: Curculionidae: Polydrosinae: Eustylini).

Em São Paulo, $P$. thunbergi adultos foram observados associados a flores de Eucalyptus sp. (PINHEIRO, 1962). No Brasil, a ocorrência dessa espécie foi ainda relatada desde a Bahia até o Rio Grande do Sul (SILVA et al., 1968).

Adultos dessa espécie medem $10 \mathrm{~mm}$ de comprimento e 4mm de largura, com coloração verde, élitros com faixas escuras e amareladas no sentido longitudinal.

No presente estudo, observou-se o $\boldsymbol{P}$. thunbergi em copas de árvores de um a quatro anos de idade, em cepas de brotações e em mudas de acácianegra. Esse inseto alimenta-se, preferencialmente, das folhas novas, com redução significativa da área foliar, o que prejudica a atividade fotossintética e o desenvolvimento da planta. Ataques severos em mudas determinam a morte da planta. A maior incidência de danos ocorre entre novembro e janeiro, quando podese observar a presença de grande número de adultos de $\boldsymbol{P}$. thunbergi em povoamentos de acácia-negra.

Não há registros de produtos para o controle de espécies de Curculionidae em $\boldsymbol{A}$. mearnsii. Isto torna o controle biológico, através de inimigos naturais, uma medida necessária, assim como estudos sobre a biologia e a etiologia do $\boldsymbol{P}$. thunbergi.

A área de cultivo da acácia-negra no Rio Grande do Sul vem crescendo, chegando hoje a extensos maciços homogêneos com vulnerabilidade para a ocorrência de pragas. Desta forma, o monitoramento e o manejo integrado de insetos como P. thunbergi são importantes para a manutenção da produtividade da acácia-negra.

Este é o primeiro registro de $\boldsymbol{P}$. thunbergi (Dalman, 1823) danificando plantas de A. mearnsii no Brasil.

\section{AGRADECIMENTOS}

À Empresa SETA S.A., pela disponibilidade das áreas de estudo e ao CNPq, pelo suporte financeiro.

\section{REFERÊNCIAS}

ANDRADE, E.N. Uma praga do eucalipto. Chácaras e quintais, v.37, n.5, p.463-465, 1928.

BORROR, D.J.; DELONG, D.M. Introdução ao estudo dos insetos. Rio de Janeiro: USAID, 1969. 653p.

OLIVEIRA, H.A. Acácia negra e tanino no Rio Grande do Sul. Porto Alegre: Tipografia Mercantil, 1960. 116p.

PEDROSA-MACEDO, J.H. (Coord). Manual de pragas florestais: pragas florestais no sul do Brasil. Viçosa: SIF/ IPEF, 1993. 112p.

PINHEIRO, J.V. Contribuição para o conhecimento de insetos em eucaliptais no Brasil. Anais Brasileiro Economia Florestal, v.14, n.14, p.245-255, 1962.

SILVA, A.G.D.A. et al. Quarto catálogo dos insetos que vivem nas plantas do Brasil, seus parasitos e predadores. Parte II - $1^{\circ}$ tomo - Insetos, hospedeiros e inimigos naturais. Rio de Janeiro: Min. de Agric., Depto. de Def. e Inspeção Agropecuária, 1968. 622p. 